\title{
ANÁLISE DA ARBORIZAÇÃO URBANA NO MUNICÍPIO DE MEDIANEIRA, PARANÁ
}

\author{
ANAL YSIS OF URBAN AFFORESTATION IN MEDIANEIRA, PARANÁ \\ Fernando Periotto ${ }^{1}$, Mateus Mestriner Pituco², Andrieli Cristina Helmann², Tiago Oliveira dos Santos², \\ Silvana Ligia Bortolotti ${ }^{3}$
}

\section{RESUMO}

A arborização urbana planejada proporciona excelência à qualidade da paisagem, abrigo às aves, invertebrados e outros seres, mitigando diversos problemas ocasionados pelo desenvolvimento urbano. Os objetivos aqui propostos foram identificar e quantificar as árvores presentes na área urbana do município de Medianeira, Paraná, gerando um inventário da arborização estudada. Para tanto foi desenvolvida uma ficha de campo no intuito de avaliar os atributos: identificação botânica, afloramento de raízes, fiação e ações executadas, calculando-se o tamanho mínimo da amostra, através de amostragem aleatória sistemática. As características viárias dos setores estudados são promissoras às futuras ações de arborização urbana executadas com qualidade e planejamento, entretanto, o manejo atual mostrou-se inadequado, resultando em diversos problemas identificados como, o estado de enraizamento das árvores elevando calçadas, exemplares frequentemente manejados através de poda drástica apresentando danos físicos, doenças e contato com a fiação da rede elétrica.

Palavras-chave: Biota urbana; Árvores; Vias públicas; Poda; Planejamento.

\section{ABSTRACT}

The planned urban forestry provides excellence in landscape quality, shelter to birds, invertebrates and other creatures, reducing several problems caused by urban development. The objectives of this study were to identify and quantify the trees present in the urban area of Medianeira city, Paraná, generating an inventory of the studied trees. So, it was developed a field record in order to raise the attributes: botanical identification, root condition, electrical grid contact and actions being performed, calculating the minimum sample size, through systematic random sampling. The characteristics of the studied sectors are promising for future actions of urban afforestation executed with quality and planning, however, the current management is inadequate, resulting in many problems identified as the condition of roots raising the sidewalks, specimens often managed through drastic pruning presenting injury, diseases and contact with the electrical grid.

Keywords: urban biota; trees; public streets; pruning; planning..

Recebido em 10.05.2016 e aceito em 21.07.2016

1 Biólogo, Dr., Professor Adjunto da Universidade Federal de São Carlos, Buri, SP Email: ferperiotto@ufscar.br

2 Engenheiros Ambientais, Universidade Tecnológica Federal do Paraná, Medianeira, PR Email: mateuspituco@hotmail.com; andrieli.utfpr@hotmail.com; engenheiro.oliveiras@gmail.com

3 Matemática, Dra., Professora Titular da Universidade Tecnológica Federal do Paraná, Medianeira, PR Email: sligie@globo.com 


\section{INTRODUÇÃO}

O acelerado crescimento das cidades somado ao desenvolvimento industrial pode ocasionar uma série de problemas ambientais, dentre eles a inexistência, a escassez e a ineficácia quanto a gestão de áreas verdes municipais, por consequência da carência de planejamento e de políticas públicas voltadas à arborização urbana.

O meio urbano, por suas necessidades de infraestrutura, modifica totalmente a cobertura vegetal original em sua área, assim sendo, a biodiversidade é erodida, e a degradação paisagística e ambiental passa a ser um problema importante a ser solucionado.

No Brasil, devido aos modelos de desenvolvimento e de ocupação adotados em muitos municípios, não há prioridade para um adequado planejamento da arborização urbana, bem como uma consciência ambiental relacionada à mesma. Nesse contexto, diversos problemas são ocasionados pelos indivíduos arbóreos existentes nas vias públicas, tais como, o rompimento de pavimentos, o contato com a rede elétrica, a interferência em redes de esgoto e pluviais, dentre outros.

Diagnosticar essas áreas é importante para a elaboração do planejamento da arborização de uma cidade Schwab et al. (2014) e, para conhecê-la é necessário efetuar um levantamento florístico no intuito de avaliar a situação e, por meio dos resultados obtidos, possibilitar as soluções possíveis para cada local (ASSUNÇÃO et al., 2014).

É fato que a arborização urbana oferece excelência à qualidade da paisagem, permite a minimização de ilhas de calor, promove quebra de vento, abrigo às aves, invertebrados e outros seres, serve como fonte de alimentos e mitiga diversos problemas proporcionados por um desenvolvimento urbano desorganizado. Os indivíduos vegetais arbóreos, em função de seu porte são os que proporcionam os maiores benefícios ambientais.

Nas vias públicas a arborização promove benefícios múltiplos nas cidades, proporcionando conforto aos habitantes através da redução da temperatura, da melhoria da qualidade do solo e do ar, além de amenizar percepções negativas geradas pela urbanização (OLDFIELD et al., 2013). Entretanto, a arborização de um município constituída sem planejamento pode ocasionar problemas por vezes irreversíveis e, ao invés de um elemento benéfico, passa a representar um foco de conflito com a estrutura urbana.

Para que o processo de arborização urbana ocorra com qualidade, se faz necessário uma série de medias a serem tomadas pelos órgãos competentes. O ponto inicial está na incorporação da mesma à legislação municipal, com sua implantação no plano diretor, bem como a criação de leis voltadas a este fim, assim, é de suma importância que se faça um levantamento das árvores existentes na área urbana levando em conta os problemas que as envolvem. 
$\mathrm{Na}$ implantação de um projeto de arborização municipal é fundamental o estudo sobre a biologia e o manejo das mudas a serem plantadas, levando em conta as características das vias, das calçadas, da rede elétrica, das redes pluviais e de esgoto. As árvores que oferecem risco devem ser substituídas, envolvendo, assim, estudos voltados às espécies ideais para cada localidade.

De acordo com Silva Filho et al. (2002), em muitas situações, o planejamento urbano deixa de incluir a arborização como equipamento a ser devidamente planejado, permitindo muitas vezes que, iniciativas particulares pontuais e desprovidas de conhecimento técnico atualizado tomem espaço com plantios irregulares de espécies sem compatibilidade com o planejamento anterior.

Existem várias razões pelas quais um inventário da arborização urbana deve ser realizado. A primeira razão está em arquitetar um programa de gestão relativo às podas, plantio, remoção e ao desenvolvimento estrutural das árvores, assim como descrito em PREFEITURA DE SÃO PAULO (2012). Outra razão está em determinar o valor total do recurso de manutenção, bem como os benefícios que a arborização é capaz de proporcionar, dentre eles, conforto térmico, despoluição visual e a conservação da natureza nas cisades INSERNHAGEN, LE BOURLEGAT e CARBONI (2009); LIN et al. (2010); OLDFIELD et al. (2013)Trabalhos florísticos desenvolvidos em áreas urbanas permitem que a arborização local seja tecnicamente monitorada e cientificamente identificada, proporcionando adequação profissional ao seu manejo. Consequência disso à população residente são os benefícios gerados, como, qualidade ambiental, valorização em aspectos ecológicos e imobiliários, conforto e qualidade de vida na área estudada e benefícios diversos à fauna e flora local.

Assim sendo, o presente estudo teve como objetivos, identificar e quantificar as árvores presentes na área urbana do município de Medianeira e seus atributos como, interferências, ações antrópicas e conflitos a elas relacionados.

\section{MATERIAL E MÉTODOS}

\section{Local de estudo}

O estudo foi realizado no município de Medianeira, situado no oeste do Paraná, cuja população estimada é de 44.523 habitantes. O município possui área territorial de $325,167 \mathrm{~km}^{2}$, com distância de 577,30 km da capital Curitiba (IBGE, 2014).

A malha viária avaliada para o estudo foi subdivida em cinco setores no intuito de possibilitar as atividades in loco, conforme descrito na Figura 1, onde o Setor A (verde), compreendeu os bairros Jardim Irene, Frimesa e Condá; Setor B (vermelho), bairro Belo 
Horizonte; Setor C (azul), área central de Medianeira composta pelos bairros São Cristovão, Centro e Cidade Alta; Setor D (rosa), bairros Independência, Panorâmico e Itaipu e Setor E (roxo), bairros Nazaré e Jardim Ipê. Não foram considerados canteiros centrais, praças, distritos municipais e condomínios fechados.

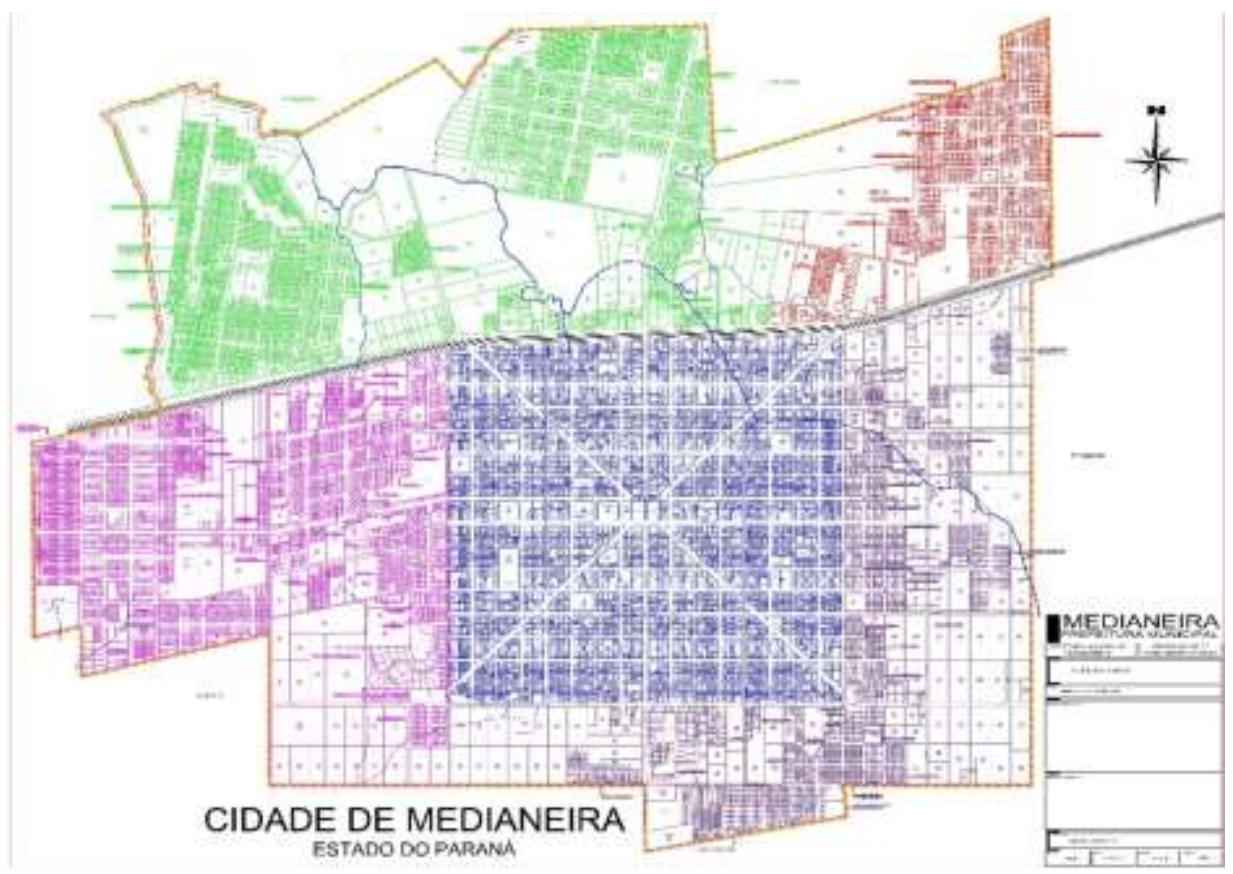

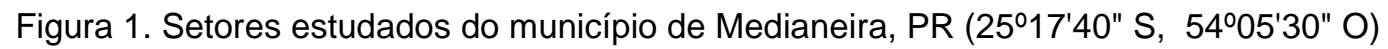

Figure 1. . Studied sectors of Medianeira city, Parana (2517'40" S, 540ㅗ' $30^{\prime \prime}$ W)

Com o intuito de auxiliar na coleta de dados foi desenvolvida uma ficha de campo baseada no trabalho de Silva Filho et al. (2002), a qual sofreu algumas alterações de acordo com os objetivos do estudo. Desse modo, foram avaliados os seguintes atributos: identificação botânica; afloramento da raiz; fiação e ações executadas.

\section{Identificação botânica}

As identificações botânicas foram realizadas através de literatura especializada na área de Botânica e por meio de registros fotográficos, de modo que cada espécie teve as suas características analisadas, sendo seus aspectos ecológicos, fenológicos, paisagísticos e urbanísticos fossem registrados.

\section{Afloramento de raízes}

No caso do fator afloramento da raiz, este foi considerado como ausente quando as raízes não se encontravam expostas, elevando o pavimento em que se localizavam. Em situações as quais essas ocasionavam algum tipo de interferência, mencionou-se o local como, calçada, construção ou leito carroçável. 


\section{Fiação elétrica}

A interferência relacionada à fiação, ou seja, de que maneira o desenvolvimento da copa arbórea se portava em relação à rede elétrica, foi avaliada da seguinte maneira: Ausente: quando a rede não estava em contato com alguma parte da árvore; Atual: quando a espécie, pelo seu crescimento normal estava em contato com a rede; Potencial: quando a espécie, pelo seu crescimento normal, apresentava um possível contato com a fiação.

\section{Ações executadas}

A ação executada ao longo do desenvolvimento do vegetal foi analisada da seguinte maneira: plantio, controle, poda de condução, poda drástica, conforme descrito em PREFEITURA DE SÃO PAULO (2012), bem como a qualidade da ação: péssima, regular, boa e ótima.

\section{Delineamento experimental}

No delineamento experimental calculou-se o tamanho mínimo da amostra conforme Barbetta (2007) de modo que, através de amostragem aleatória sistemática, obteve-se o total de quadras envolvidas nos cinco setores de estudo, ou seja, no setor A: 17, setor B: 15, setores $\mathrm{C}$ e E: 16 e no setor D: 18 quadras, totalizando, assim, uma amostragem com o número total igual a 66 quadras. Todos os dados levantados in loco foram compilados em planilhas e gráficos do software Microsoft Excel, de modo que as análises estatísticas foram realizadas com auxílio do software Bioestat versão 5.0.

\section{RESULTADOS E DISCUSSÃO}

\section{Identificação botânica}

Foram levantados 2084 indivíduos arbóreos, sendo 429 no setor A, 435 no setor B, 447 no setor C, 502 no setor D e 271 no setor $E$, dentre as quais foram identificadas 80 espécies arbóreas pertencentes a 37 famílias botânicas.

$\mathrm{Na}$ Tabela 1 foram dispostos detalhes das espécies de maior relevância encontradas no levantamento efetuado, ou seja, as que atingiram número superior a 10 indivíduos, constituindo assim, a frequência relativa e a ocorrência predominante na cidade. 
Tabela 1. Lista de espécies encontradas no inventário da arborização da cidade de Medianeira, PR Table 1. Species found in the inventory of trees in the city of Medianeira, PR

\begin{tabular}{|c|c|c|c|c|c|}
\hline Família & Gênero e espécie & Nome popular & \begin{tabular}{|l|} 
Número de \\
indivíduos
\end{tabular} & $\begin{array}{l}\text { Frequência } \\
\text { relativa (\%) } \\
\end{array}$ & Ocorrência \\
\hline Anacardiaceae & $\begin{array}{l}\text { Mangifera indica L. } \\
\text { Schinus molle L. }\end{array}$ & $\begin{array}{c}\text { Mangueira } \\
\text { Aroeira salsa }\end{array}$ & $\begin{array}{c}570 \\
94\end{array}$ & $\begin{array}{c}27,35 \\
4,5\end{array}$ & $\begin{array}{l}\text { Exótica } \\
\text { Nativa }\end{array}$ \\
\hline \multirow{2}{*}{ Arecaceae } & $\begin{array}{l}\text { Roystonea oleracea } \\
\text { (Jacq.) O. F. Cook. }\end{array}$ & $\begin{array}{l}\text { Palmeira } \\
\text { imperial }\end{array}$ & 21 & 1,01 & Exótica \\
\hline & $\begin{array}{c}\text { Syagrus romanzoffiana } \\
\text { (Cham.) }\end{array}$ & Jerivá & 31 & 1,49 & Nativa \\
\hline Bignoniaceae & $\begin{array}{c}\text { Handroanthus } \\
\text { chrysotrichus (Mart. ex } \\
\text { A.DC.) }\end{array}$ & Ipê amarelo & 35 & 1,68 & Nativa \\
\hline \multirow{2}{*}{ Caesalpinioideae } & $\begin{array}{c}\text { Caesalpinia pluviosa } \\
\text { DC. }\end{array}$ & Sibipiruna & 117 & 5,61 & Nativa \\
\hline & Cassia fistula L. & $\begin{array}{l}\text { Acassia } \\
\text { imperial }\end{array}$ & 25 & 1,20 & Exótica \\
\hline Chrysobalanaceae & $\begin{array}{l}\text { Licania tomentosa } \\
\text { (Benth.) Fritsch }\end{array}$ & Oiti & 72 & 3,45 & Nativa \\
\hline Combretaceae & Terminalia catappa L. & Sete copas & 54 & 2,59 & Exótica \\
\hline Fabaceae & $\begin{array}{c}\text { Delonix regia (Hook.) } \\
\text { Raf. }\end{array}$ & Flamboyant & 11 & 0,53 & Exótica \\
\hline \multirow{3}{*}{ Lauraceae } & $\begin{array}{c}\text { Nectandra } \\
\text { megapotamica } \\
\text { (Spreng.) Mez. }\end{array}$ & Canelinha & 25 & 1,20 & Nativa \\
\hline & Nectandra sp. & Canela & 52 & 2,50 & Nativa \\
\hline & $\begin{array}{l}\text { Persea americana P. } \\
\text { Mill. }\end{array}$ & Abacateiro & 27 & 1,3 & Exótica \\
\hline Lythraceae & $\begin{array}{l}\text { Lagerstroemia indica } \\
\text { (L.) Pers. }\end{array}$ & Resedá & 89 & 4,27 & Exótica \\
\hline Magnoliaceae & Magnolia champaca L. & Magnólia & 14 & 0,67 & Exótica \\
\hline Melastomataceae & $\begin{array}{l}\text { Tibouchina granulosa } \\
\text { (Desr.) Cogn. }\end{array}$ & Quaresmeira & 17 & 0,82 & Nativa \\
\hline Meliaceae & Melia azedarach L. & Santa bárbara & 13 & 0,62 & Exótica \\
\hline \multirow[b]{2}{*}{ Moraceae } & Ficus auriculata Lour. & Figueira chilena & $\begin{array}{l}71 \\
96\end{array}$ & $\begin{array}{l}3,41 \\
461\end{array}$ & Exótica \\
\hline & $\begin{array}{l}\text { Ficus gardneriana } \\
\text { (Miq.) Miq. }\end{array}$ & Figueira & 23 & 1,10 & Nativa \\
\hline \multirow{3}{*}{ Myrtaceae } & $\begin{array}{c}\text { Eugenia involucrata } \\
\text { DC. }\end{array}$ & $\begin{array}{c}\text { Cereja } \\
\text { brasileira }\end{array}$ & 53 & 2,54 & Nativa \\
\hline & $\begin{array}{l}\text { Eugenia uniflora L. } \\
\text { Psidium guajava L. }\end{array}$ & $\begin{array}{l}\text { Pitanga } \\
\text { Goiabeira }\end{array}$ & $\begin{array}{l}43 \\
56\end{array}$ & $\begin{array}{l}2,06 \\
2,69\end{array}$ & $\begin{array}{l}\text { Nativa } \\
\text { Nativa }\end{array}$ \\
\hline & $\begin{array}{c}\text { Syzygium jambolanum } \\
\text { (Lam.) DC. }\end{array}$ & Jambolão & 15 & 0,72 & Exótica \\
\hline Proteaceae & $\begin{array}{l}\text { Grevillea robusta } \\
\text { A.Cunn.,ex R.Br. }\end{array}$ & Grevilha & 13 & 0,62 & Exótica \\
\hline Rhamnaceae & $\begin{array}{l}\text { Hovenia dulcis Hovenia } \\
\text { dulcis Thunb. }\end{array}$ & Uva japonesa & 22 & 1,06 & Exótica \\
\hline \multirow{2}{*}{ Rosaceae } & $\begin{array}{l}\text { Eriobotrya japonica } \\
\text { (Thunb.) Lind. }\end{array}$ & Ameixeira & 59 & 2,83 & Exótica \\
\hline & Prunus persica L. & Pêssego & 13 & 0,62 & Exótica \\
\hline \multirow{3}{*}{ Rutaceae } & Citrus limonum L. & Limoeiro & 73 & 3,50 & Exótica \\
\hline & $\begin{array}{c}\text { Citrus sinensis (L.) } \\
\text { Osbeck. }\end{array}$ & Laranjeira & 37 & 1,78 & Exótica \\
\hline & $\begin{array}{c}\text { Murraya paniculata (L.) } \\
\text { Jack }\end{array}$ & Murta & 76 & 3,65 & Exótica \\
\hline
\end{tabular}


Com os dados exibidos na Tabela 1 foi possível verificar a ocorrência das espécies identificadas, de modo que as exóticas representaram 67,8\% (1299 indivíduos) e as espécies nativas 32,2\% (618 indivíduos), de acordo com as espécies com número superior a 10 indivíduos arbóreos, resultando em 1917 desses.

As espécies com as maiores frequências de ocorrências foram, Mangifera indica representando 27,35\%, Caesalpinia pluviosa, 5,61\%, Ficus benjamina, 4,61\% e Schinus molle representando $4,51 \%$ do universo total, ou seja, 2084 indivíduos.

Em relação ao número expressivo de espécies exóticas identificadas, confirmou-se os dados obtidos por outros autores (BLUM; BORGO; SAMPAIO, 2008; LUNDGREN; SILVA; ALMEIDA, 2013) em trabalhos realizados em distintos municípios brasileiros e de outros países.

Sjöman, Östberga e Bühler, (2012) pesquisaram a diversidade biológica arbórea em dez grandes cidades da Normandia por meio de arquivos atualizados que as prefeituras municipais mantinham e, constataram que, em todas havia ocorrência de árvores exóticas e $70 \%$ das cidades possuíam um maior número de árvores exóticas estabelecidas em relação às nativas.

O plantio de exóticas tem seus pontos positivos, especialmente no que se refere às características paisagísticas, esplendor e perfume de suas floradas e, por vezes, portes adequados, contudo, pontos negativos como percentual excessivo desses indivíduos na arborização urbana, falta de representatividade da flora local e suas características como invasoras também são discutidas.

De acordo com Ziller (2001) as plantas exóticas são hoje consideradas a segunda maior ameaça mundial à biodiversidade, perdendo apenas para a destruição de habitats pela exploração humana direta. Ainda segundo esse autor, as espécies exóticas podem causar diversos danos ao ambiente, além da perda de biodiversidade, como modificação dos ciclos e características naturais dos ecossistemas atingidos, alterações na fisionomia da paisagem natural, e por vezes, expressivas consequências econômicas. Esses motivos indicam a importância em priorizar o plantio de espécies nativas.

Assim sendo, a crescente substituição da flora nativa pela exótica pode, de fato, ser considerada problemática, pois altera o ambiente natural que resta nos centros urbanos, uniformizando as paisagens de diferentes cidades e contribui para a redução da biodiversidade no meio urbano, dissociando-o do contexto ambiental onde se insere (MACHADO et al., 2006).

Uma solução a tal problemática está no planejamento e execução de planos de arborização urbana em municípios que se comprometam zelar pela biodiversidade local, os quais podem gerar demanda de plantio de espécies vegetais nativas que contenham 
características adequadas às necessidades de um plantio de indivíduos arbóreos e arbustivos em áreas urbanizadas.

Assim sendo, segundo Souza, Dodonov e Dortez (2012), é importante que a diversidade da espécie seja respeitada e que se dê preferência às árvores comuns da região. $A$ regra número um de uma saudável política de arborização urbana é a diversificação das espécies, desde que sejam distribuídas nas ruas de uma forma estética e paisagística.

Uma escolha técnica e direcionada das espécies nativas para a arborização urbana é essencial, por motivos de estabelecimento e manutenção viáveis para cada indivíduo plantado. Para tanto, um horto ou viveiro de mudas florestais precisa estar estabelecido com um aporte em número e em variabilidade apropriados, para suprir as necessidades em momentos de plantio e de reposição dessa arborização.

\section{Afloramento de raízes}

No diagnóstico sobre afloramento da raiz (Figura 2), nos cinco setores amostrados, foi predominante a ausência desse problema, 81,05\%. O afloramento em calçadas, $18,52 \%$ foi o de maior ocorrência, certamente por inadequações de planejamento quanto às espécies escolhidas para o plantio, por características de seus portes avantajados ou pela biologia de crescimento dos indivíduos registrados, os quais ocasionam o soerguimento das calçadas através do crescimento superficial de suas raízes no solo.

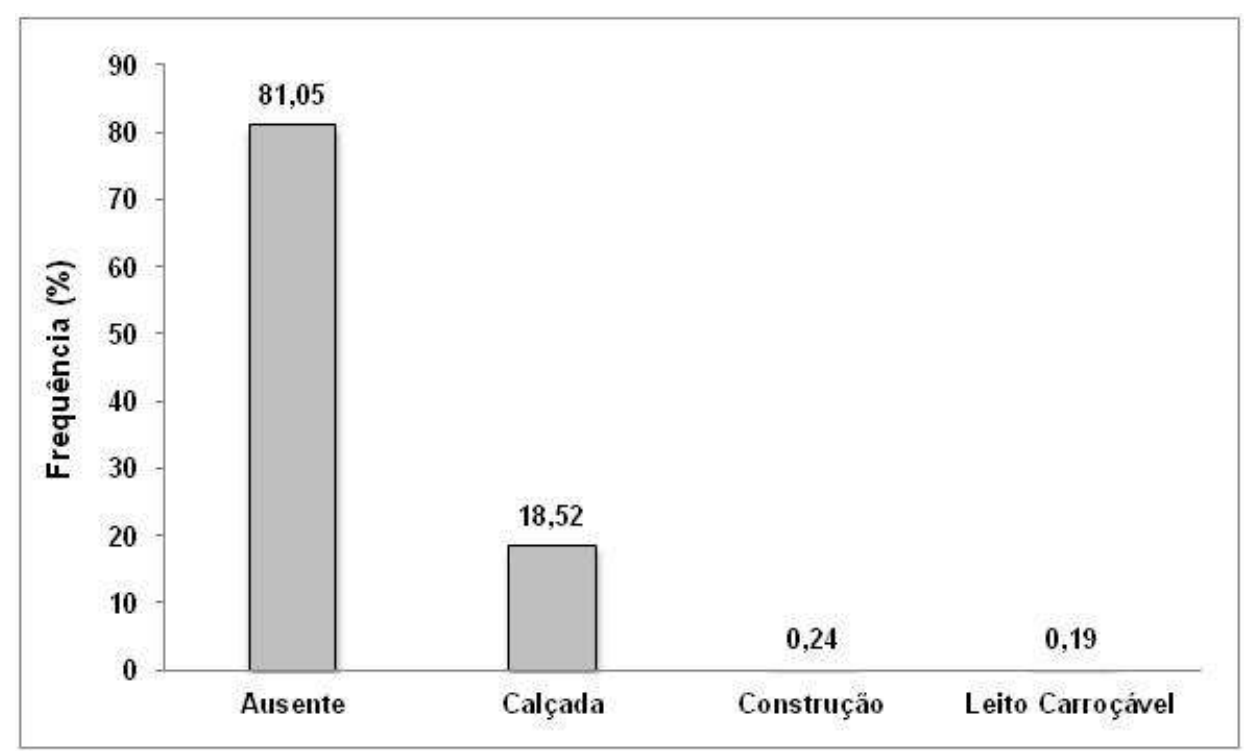

Figura 2. Atributo "afloramento da raiz" nos setores estudados, Medianeira, PR Figure 2. Attribute "outcrop root" in the studied sectors, Medianeira, PR

Nesse sentido, Sartori e Balderi (2011) indicam que determinadas espécies, como Ficus benjamina, por exemplo, possuem tendência de gerar problemas futuros, pois alcançam 
grande porte e apresentam raízes tabulares que crescem para os lados e normalmente ficam expostas. Tais fatos demonstram que $F$. benjamina e outras espécies arbóreas têm potencial para gerar problemas principalmente com calçamentos e demais pavimentações. Miranda e Carvalho (2009) sugerem que a arborização em calçadas em que a fachada residencial está diretamente na rua, não deve ser a mesma utilizada em áreas mais abertas, nesse caso, devem ser indicadas espécies arbustivas de pequeno porte para o plantio.

Em determinados casos, as raízes das árvores agem de forma diferente no mesmo local. Não existem razões óbvias por raízes de algumas árvores estarem causando danos, enquanto as raízes de outras árvores de porte semelhante da mesma espécie não ocasionarem problemas. No entanto, tais problemas parecem estar mais relacionados à idade da árvore, às condições de crescimento desde a fase de muda até o plantio em via urbana, ao crescimento superficial de raízes e ao volume de enraizamento de cada espécie.

A maneira mais eficaz de evitar danos em pavimentação ocasionados por raízes de uma árvore é a adequação de um espaço para o seu desenvolvimento, de forma a evitar que as redes de abastecimento de água, drenagem pluvial, calçadas ou cisternas possam ser afetadas. Embora cada espécie tenha um padrão particular de arquitetura das raízes, o solo é o seu principal modelador. Geralmente, o plantio de árvores em solos compactados favorece uma acomodação superficial das raízes e, solos com essa característica são comuns em meio urbano, como resultado do tráfego frequente de equipamentos pesados e pedestres, sejam extremamente compactados, superficial e subsuperficialmente, ocorrendo nestes solos a remoção ou alteração de perfis e camadas e suas propriedades químicas e físicas são modificadas, o que acaba provocando uma situação de difícil correção (CADORIN; MELLO; MONTEMEZZO, 2013).

O plantio arbóreo não planejado, conforme foi observado nesse estudo, pode acarretar diversos problemas e conflitos como, a necessidade de gastos financeiros para manutenção em reformas de calçadas, a retirada de raízes resultando em possíveis danos permanentes no equilíbrio das árvores ou a exposição à fungos e bactérias causadores de doenças, queda da árvore por poda radicular sem critérios, bem como a propiciação ao maior número de acidentes aos transeuntes.

Conforme afirmam Watson et al. (2014), os ambientes urbanos em que as árvores crescem são bastante diferentes das áreas naturais, porém, os mesmos precisam fornecer os mesmos recursos de desenvolvimento para que ocorra a manutenção de um equilíbrio saudável entre a copa, porção fornecedora e consumidora de energia, usuária de nutrientes e água e do sistema radicular, fornecedor de água, nutrientes e consumidor de energia. $\mathrm{O}$ desafio de gestão pública, portanto, está em proporcionar um ambiente urbano que funcione de 
modo similar ao ambiente natural, embora sua aparência seja, muitas vezes, completamente diferente.

\section{Fiação elétrica}

A Figura 3 explicita a frequência da interferência relacionada à fiação encontrada no estudo, sendo a maior porcentagem, 49,0\% como "atual", seguida de 36,9\% como "ausente" e a menor porcentagem 14,1\% como "potencial", indicando que mais da metade dos indivíduos levantados continham problemas relacionados à fiação elétrica por questões do desenvolvimento arbóreo atual e futuro.

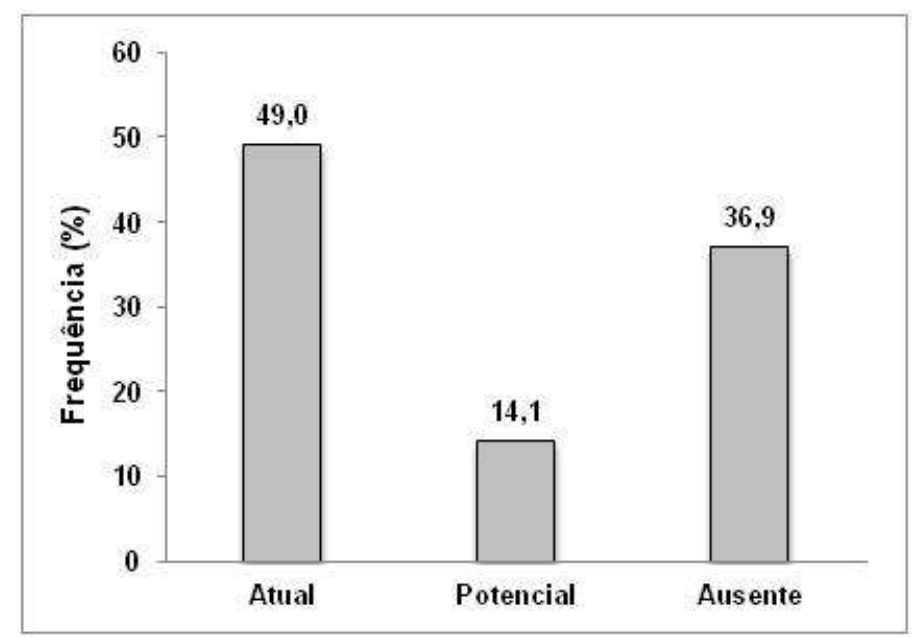

Figura 3. Atributo "fiação" nos setores estudados, Medianeira, PR

Figure 3. Attribute "wiring" in the studied sectors, Medianeira, PR

A disputa entre as árvores nas calçadas e as redes elétricas pelo mesmo espaço é, sem dúvida, um dos principais problemas existentes na arborização viária de uma cidade, principalmente porque a tendência de plantar arbustos ou espécies de pequeno porte para que estes não interfiram na rede, assim como a poda dos galhos que já estão comprometidos com ela, ainda são as opções mais usadas pelos órgãos responsáveis (VELASCO; LIMA; COUTO, 2006).

Conflitos entre árvores e redes elétricas são comuns, nos quais, a arborização e os demais componentes urbanos disputam espaço físico e recursos para manutenção. Esses conflitos podem ser mitigados através dos artifícios da poda efetuada com critérios técnicos, e através da escolha de mudas adequadas nos momentos de plantio.

Uma das dificuldades na implantação da arborização urbana está em conciliar as espécies escolhidas com os componentes urbanos existentes em cada ambiente urbano de plantio. No caso específico da eletricidade, sabe-se que a mesma confere altos riscos às pessoas, mesmo em baixas tensões. 
Potencialmente, todas as árvores carregam uma determinada quantidade de risco inerente. A proximidade ao cabeamento de energia elétrica deve ser prevista, conforme a disposição da rede e a biologia da espécie a ser selecionada para plantio na via pública. $\mathrm{Na}$ gestão da arborização urbana, a avaliação da integridade estrutural de uma árvore e do seu entorno pode determinar sua situação de risco, no entanto, a decisão final quanto ao manejo da árvore dependerá ainda da percepção do gerenciador na avaliação das medidas de controle dos riscos associados (CEMIG, 2011).

Vale salientar que foi encontrado um considerável número de indivíduos arbóreos que ocasionarão problemas futuros à fiação, desse modo, o manejo de cada um desses deverá obedecer a podas ou eliminação executadas por profissionais do poder público ou das companhias de distribuição. No entanto, quando podas são mal executadas, ocorre exposição à doenças e grande risco de mortalidade futura.

Assim sendo é componente da gestão da arborização urbana a identificação e a avaliação dos riscos potenciais associados às árvores, procurando gerenciá-los dentro de limites aceitáveis, estabelecidos tanto no âmbito técnico e profissional, quanto no âmbito da segurança pública, patrimonial, ambiental e de responsabilidade civil, tendo em vista os objetivos pretendidos para a arborização (CEMIG, 2011).

Portanto, as árvores urbanas quando bem implantadas e manejadas transmitem múltiplos benefícios e estão longe de serem caracterizadas como um problema. Os benefícios podem ser de ordem estética, relacionados principalmente a efeitos visuais que as plantas fornecem, proporcionando um contato do homem com a natureza, produzindo um efeito harmônico através de suas linhas suaves e orgânicas, formas, cores e texturas, criando paisagens específicas, proporcionando identidade às ruas (SCHALLENBERGER et al., 2010).

\section{Ações executadas}

Foi possível observar a relação quanto à qualidade e ao tipo de ações executadas encontradas nos locais de estudo, como por exemplo, se o tipo de poda realizada se enquadrou nos níveis de ótima, boa, regular ou péssima. Registrou-se um alto índice de poda drástica (pesada) nas árvores levantadas, observando como mais frequentes, as ações de qualidade péssima, 27,35\%, e regular, 7,15\% (Figura 4). 


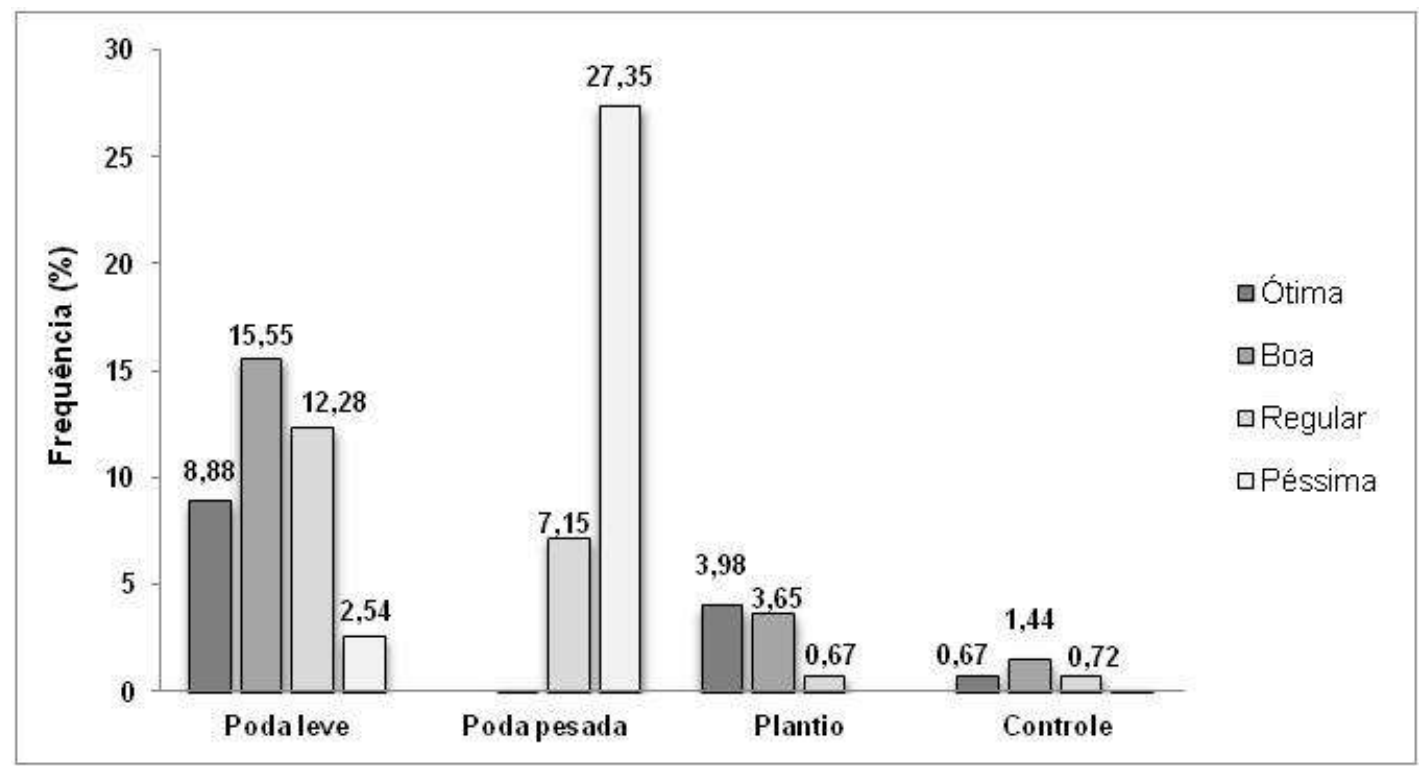

Figura 4. Atributo "ação executada" nos setores estudados, Medianeira, PR Figure 4. Attribute "action taken" in the studied sectors, Medianeira, PR

A poda, na arborização urbana, segundo a Prefeitura de São Paulo (2012), deveria visar basicamente: uma forma adequada à sua estrutura ao longo de seu desenvolvimento (poda de formação); a eliminação de ramos mortos, danificados, doentes ou praguejados (poda de limpeza); a remoção de partes da árvore que colocam em risco a segurança das pessoas (poda de emergência) e, por fim, a retirada de partes que possuem potencial para interferir ou causar danos incontornáveis às edificações ou aos equipamentos urbanos (poda de adequação), sendo esta última, equivalente a poda de condução.

Sob tal foco, a poda deve ser executada somente para conduzir a parte aérea, especialmente a copa, de uma árvore no sentido de ocupar o espaço disponível e, excepcionalmente para reduzir ou delimitar o seu volume, evitando que a mesma seja "mutilada" por podas drásticas ou executadas com imperícia (PREFEITURA DE SÃO PAULO, 2012).

Desse modo, desde que bem executada, através de critérios técnicos, a poda não proporcionará desequilíbrios ou a facilitação para ingresso de doenças, dentre outros e diversos problemas no indivíduo arbóreo. Por fim, a poda drástica ou pesada não deve ser praticada, mas sim o planejamento adequado da muda a ser estabelecida em cada local escolhido, levando em conta entre diversas características do vegetal, o padrão de crescimento de copa e de enraizamento.

Por meio das características viárias observadas e registradas nos setores estudados, o manejo realizado atualmente mostra-se inadequado, resultado nos diversos problemas aqui expostos, de modo que, boa parte dos indivíduos estudados apresentou algum tipo de 
problema, ou seja, exemplares frequentemente manejados através de poda drástica, sem indícios de critérios técnicos (Figura 5).

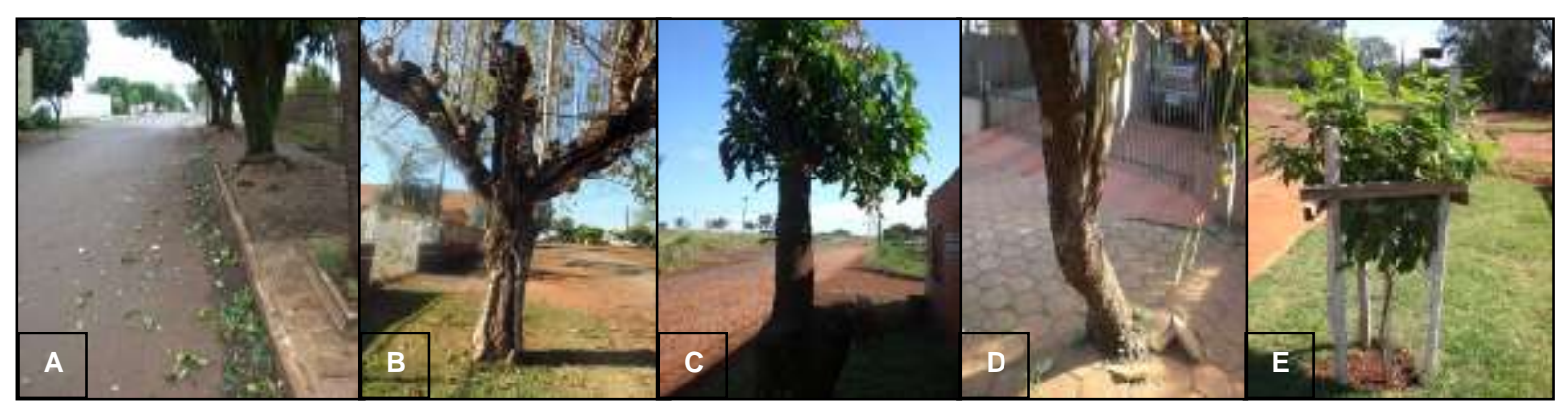

Figura 5. Características gerais de indivíduos identificados. A e C: Mangifera indica (queda de frutos, afloramento de raízes e poda pesada); B: Magnolia champaca (poda drástica resultando em doenças); D: Bauhinia forficata (afloramento de raízes e ausência de área permeável); E: Licania tomentosa (muda adequadamente plantada e protegida)

Figure 5. General characteristics of identified individuals. A and C: Mangifera indica (fruit drop, outcropping of roots and heavy pruning); B: Magnolia champaca (drastic pruning resulting in disease); D: Bauhinia forficata (outcrop of roots and absence of permeable area); E: Licania tomentosa (tree properly planted and protected)

Os dados de maior relevância diagnosticados (Figura 4) referem-se aos tipos de poda leve e drástica. Esta última, prática desaconselhável no manejo de árvores urbanas, foi uma constante na arborização urbana pesquisada, resultando em estado regular ou péssimo das árvores atingidas.

Assim sendo, as condições de vigor e de saúde arbórea podem apresentar problemas como desequilíbrio das copas, doenças em estágios avançados ou irreversíveis, pois a injúria mecânica pode descaracterizar totalmente a arquitetura do vegetal e ocasionar morte.

Martins; Andrade; De Angelis (2010) afirmam que quando a poda é conduzida inadvertidamente, sem o uso de técnicas especificas, prejudica a planta, deixando-a exposta a agentes externos e desconfigurando sua arquitetura. A exposição do lenho permite a entrada de microrganismos e artrópodes que degradam a madeira e afetam negativamente sua fitossanidade. Os aspectos fitossanitários negativos mais notados em árvores urbanas são os ataques por pragas e doenças, responsáveis pela biodeterioração do vegetal.

Caso características não sejam levadas em conta durante a arborização, como por exemplo o porte, podem ocorrer conflito entre as árvores e os equipamentos urbanos tais como fiações elétricas, encanamentos, calhas, muros e postes de iluminação, dentre outros, o que pode levar inclusive a danos e a manejo inadequado das próprias árvores (SOUZA; DODONOV; DORTEZ, 2012).

As intervenções antrópicas e interferências relativas a cada indivíduo estudado, ações como, afloramento da raiz e ramificações próximas à fiação, sinalizam a ausência de planejamento de plantio que respeite a biologia da espécie estabelecida nas vias públicas. 
Conforme observado nesse estudo e descrito na literatura (SCHALLENBERGER et al., 2010; CEMIG, 2011; SOUZA; DODONOV; DORTEZ, 2012; WATSON et al., 2014), o planejamento de plantio tem início no viveiro de mudas e deve ser executado através de embasamento técnico, pois cada espécie tem as suas características de enraizamento, crescimento caulinar, ramificação, floração e frutificação; fatores que podem ser favoráveis ou até condenáveis, dependendo da localização em que a árvore for instalada.

\section{CONSIDERAÇÕES FINAIS}

As características viárias dos cinco setores estudados são promissoras para futuras ações de arborização urbana efetuadas com qualidade e planejamento, entretanto, o manejo que vem sendo realizado na atualidade mostra-se inadequado, resultando em diversos problemas descritos nesse estudo.

O estado crítico de muitas das árvores estudadas, em que situações de doenças ou algum tipo de problema foi observado é fruto de um manejo efetuado sem qualquer critério técnico, onde a poda drástica é a prática comum e a que deve ser abolida, substituída.

As intervenções antrópicas e interferências relativas a cada indivíduo estudado, ações como, afloramento da raiz e ramificações próximas à fiação, indicam para uma grande porcentagem dos indivíduos estudados a ausência de planejamento de plantio que respeite a biologia de cada espécie implantada nas vias públicas.

Por fim, devido as diversas importâncias científicas que a arborização urbana pode oferecer aos cidadãos, ao espaço urbano e à biota local, esta merece especial atenção do poder público. Assim sendo, sugere-se que seja implantado no município estudado o planejamento de plantio e manejo adequado para podas, e acompanhamento e remoção das espécies arbóreas urbanas.

\section{REFERÊNCIAS}

ASSUNÇÃO, K. C. de; LUZ, P. B. da; NEVES, L. G.; SOBRINHO, S. de P. Levantamento quantitativo da arborização de praças da cidade de Cáceres/MT. Revista da Sociedade Brasileira de Arborização Urbana, Piracicaba, v. 9, n. 1, p.123-132, 2014.

BARBETTA, P. A. Estatística Aplicada às Ciências Sociais. - Florianópolis: - UFSC, 2007. $318 \mathrm{p}$. 
BLUM, C. T.; BORGO, M.; SAMPAIO, A. C. F. Espécies exóticas invasoras na arborização de vias públicas de Maringá - PR. Revista da Sociedade Brasileira de Arborização Urbana, Piracicaba, v. 3, n. 2, p. 78-97, 2008.

CADORIN, D. A.; MELLO, N. A.; MONTEMEZZO, E. Aspectos químicos e morfológicos dos solos urbanos utilizados pelas espécies Lagerstroemia indica L., Schinus molle L. e Bauhinia variegata L., em três bairros da cidade de Pato Branco - PR. Revista da Sociedade Brasileira de Arborização Urbana, Piracicaba, v. 8, p. 39-51, 2013.

Companhia Energética de Minas Gerais (CEMIG). Manual de arborização. Belo Horizonte: Cemig / Fundação Biodiversitas, 2011. 112p. Disponível em: < http://www.cemig.com.br/ sites/imprensa/pt-br/Documents/Manual_Arborizacao_Cemig_Biodiversitas.pdf >. Acesso em: 01 Set. 2015.

INSERNHAGEN, I.; LE BOURLEGAT, J. M. G.; CARBONI, M. Trazendo a riqueza arbórea regional para dentro das cidades: possibilidades, limitações e benefícios. Revista da Sociedade Brasileira de Arborização Urbana, Piracicaba, v. 4, n. 2, p.117-138, 2009.

LIN, T. P.; MATZARAKIS; A.; HWANG, R. L. Shading effect on long-term outdoor thermal comfort. Building and Environment, v. 45, p. 213-221, 2010.

LUNDGREN, W. J. C.; SILVA, L. F.; ALMEIDA, A. Q. Influência das espécies exóticas arbóreas urbanas na área de cobertura da cidade de serra talhada - PE. Revista da Sociedade Brasileira de Arborização Urbana, Piracicaba, v. 8, n. 3, p. 96-107, 2013.

MARTINS, L. F. V.; ANDRADE, H. H. B.; DE ANGELIS, B. L. D. Relação entre podas e aspectos fitossanitários em árvores urbanas na cidade de Luziana, Paraná. Revista da Sociedade Brasileira de Arborização Urbana, v. 5, n. 4, p. 141-155, 2010.

MACHADO, R. R. B.; MEUNIER, I. M. J.; SILVA, J. A. A.; CASTRO, A. A. J. F. Árvores nativas para a arborização de Teresina, Piauí. Revista da Sociedade Brasileira de Arborização Urbana, Piracicaba, v. 1, n. 1, p. 10-18. 2006.

MIRANDA, T. O; CARVALHO, S. M. Levantamento quantitativo e qualitativo de indivíduos arbóreos presentes nas vias do bairro da Ronda em Ponta Grossa, PR. Revista da Sociedade Brasileira de Arborização Urbana, Piracicaba, v. 4, n. 3, p. 143- 157, 2009.

OLDFIELD, E. E.; WARREN, R. J.; FELSON, A. J.; BRADFORD, M. A. Challenges and future directions in urban afforestation. Journal of Applied Ecology, England, v. 50, n. 5, p. 11691177, 2013.

PREFEITURA DE SÃO PAULO. Manual Técnico de Poda de Árvores. Secretaria do Verde e do Meio Ambiente. Secretaria de Coordenação das Subprefeituras. 2012. 62 p.

SARTORI, R. A; BALDERI, A. P. Inventário da arborização urbana do município de Socorro, SP e proposta de um índice de danos à infraestrutura das cidades. Revista da Sociedade Brasileira de Arborização Urbana, Piracicaba, v. 6, n. 4, p. 68-89, 2011.

SCHALLENBERGER, L. S.; ARAÚJO, A. J.; ARAÚJO, M. N.; DEINER, L. J.; MACHADO, G. O. Avaliação da condição de árvores urbanas nos principais parques e praças do Município de Irati - PR. Revista da Sociedade Brasileira de Arborização Urbana, Piracicaba, v. 5, n. 2, p. 105-123, 2010. 
SCHWAB, N. T.; GIRARDI, L. B.; NEUHAUS, M.; BACKES, F. A. A. L.; BELLÉ, R. A.; MENEGAES, J. F. Diversidade florística do bairro Nossa Senhora das Dores em Santa Maria, RS. Revista Brasileira de Horticultura Ornamental, Campinas, v. 20, n. 2, p.155-162, 2014.

SILVA FILHO, D. F. da; PIZETTA, P. U. C.; ALMEIDA, J. B. S. A. de; PIVETTA, K. F. L.; FERRAUDO, A. S. Banco de dados relacional para cadastro, avaliação e manejo da arborização em vias públicas. Revista Árvore, Viçosa, v. 26, n. 5, p. 629-642, 2002.

SJÖMAN H.; ÖSTBERGA, J.; BÜHLER, O. Diversity and distribution of the urban tree population in ten major Nordic cities. Urban Forestry \& Urban Greening, Champaign IL, v. 11, 1, p. 31-39, 2012.

SOUZA, C. da S. e; DODONOV, P.; CORTEZ, R. B. Diversidade, fitossanidade e adequação ao ambiente urbano de árvores de rua em um bairro na cidade de Ourinhos, SP, Brasil. Revista da Sociedade Brasileira de Arborização Urbana, Piracicaba, v. 7, n. 4, p. 77-89, 2012.

WATSON, G. W.; HEWITT, A. M.; CUSTIC, M.; LO, M. The Management of Tree Root Systems in Urban and Suburban Settings: A review of soil Influence on root growth. Arboriculture \& Urban Forestry, Champaign IL, v. 40, 4, p. 193-217, 2014.

VELASCO, G. D. N.; LIMA, A. M. L. P.; COUTO, H. T. Z. Análise Comparativa dos custos de diferentes redes de distribuição de energia elétrica no contexto da arborização urbana. Revista Árvore, Viçosa, v. 30, p. 679-686, 2006.

ZILLER, S. R. Os processos de degradação ambiental originados por plantas exóticas invasoras. Ambiente Brasil. 2001. Instituto Hórus de Desenvolvimento e Conservação Ambiental. Disponível em: < http://www.institutohorus.org.br/download/artigos/Ciencia \%20Hoje.pdf> Acesso em: 20 Set. 2015. 